ISSN: 2689-9418

Volume 4, Issue 4, 2021 (pp. 59-69)

www.abjournals.org

\title{
FACTORS INFLUENCING NURSES' INVOLVEMENTS AND UTILIZATIONS OF RESEARCH FINDINGS AMONG NURSES IN A TEACHING HOSPITAL, SOUTH WEST, NIGERIA
}

\author{
Sowunmi Christiana Olanrewaju ${ }^{1}$, Olajide Adetunmise Oluseyi ${ }^{*}$, \\ Adenipekun Rhoda Adedoyin ${ }^{3}$, Fadipe Ololade Omolayo ${ }^{4}$ \\ and Ajibade Bayo Lawal ${ }^{5}$
}

\footnotetext{
${ }^{1}$ Associate Professor, Department of Maternal and Child Health, School of Nursing, Babcock University, Ilisan-Remo, Ogun State, Nigeria. lanresowunmi @ hotmail.com +2348023500321

${ }^{* 2}$ Faculty of Nursing Sciences, Ladoke Akintola University of Technology, Ogbomoso, Oyo state,

Nigeria. Email: adetunmiseolajide1@ gmail.com +2348037287328

${ }^{3}$ Nursing Officer, Ekiti State University Teaching Hospital, Ekiti State, Nigeria Email: adenipekunrhoda@gmail.com +2348066135978

${ }^{4}$ Lagos State University Teaching Hospital, Ikeja. Email: ladirolarola@yahoo.com

${ }^{5}$ Faculty of Nursing Sciences, Ladoke Akintola University of Technology, Ogbomoso, Oyo state, Nigeria. Email: blajibade@ lautech.edu.ng
}

\begin{abstract}
Cite this article:
Sowunmi C.O., Olajide A.O., Adenipekun R.A., Fadipe O.O., Ajibade B.L. (2021), Factors Influencing Nurses' Involvements and Utilizations of Research Findings Among Nurses in a Teaching Hospital, South West, Nigeria. African Journal of Health, Nursing and Midwifery 4(4), 59-69. DOI: 10.52589/AJHNMJZN8F7OQ.
\end{abstract}

\section{Manuscript History}

Received: 10 June 2021

Accepted: 7 July 2021

Published: 20 July 2021

Copyright $\odot 2020$ The Author(s). This is an Open Access article distributed under the terms of Creative Commons AttributionNonCommercial-NoDerivatives 4.0 International (CC BY-NC-ND 4.0), which permits anyone to share, use, reproduce and redistribute in any medium, provided the original author and source are credited.
ABSTRACT: Background: Nursing is a profession that is concern with ensuring high quality of patient care. To providing quality care, participation in research and research utilization is very necessary. Objective: This study was designed to study factors influencing nurses' involvement in research and utilization of research findings among nurses of a Teaching Hospital, South west, Nigeria. Method: A descriptive design was used. Convenient sample technique was used to select 198 Nurses and Self-developed questionnaire with reliability index of 0.875 was used for data collection. Data collected were analyzed using SPSS package. Descriptive and inferential statistics were used to test the hypotheses and results were presented in tables. Result: The outcome of the study showed that 153(77.3) have never carried out any research while70 (35.4\%) have never make use of research findings. Factors such as time, organizational policy, mentorship, funds and knowledge of research are some of the major factors influencing the involvement of nurses in research while awareness of research findings, time to read research findings, support from colleague, unpublished research influenced utilization of research findings. There was a significant relationship between: support from colleagues and nurses' utilization of research findings $(p=0.001)$; between unpublished research and nurses' utilization of research findings $(p$-value $=0.000)$; between time to implement new ideas and the utilization of research findings by nurses $(p=0.005)$; between organizational support and nurses' utilization of research findings ( $p=$ 0.001); between the presence of research committee and nurses' utilization of research findings $(p=0.000)$. Conclusion; numerous factors highlighted above are noted to influence nurse's participation and utilization of research findings; hence, a multidimensional approach should be applied in solving the problem.

KEYWORDS: Factors, Nurses, Nurses' involvement, Research Utilization. 
ISSN: 2689-9418

Volume 4, Issue 4, 2021 (pp. 59-69)

www.abjournals.org

\section{INTRODUCTION}

Nursing is an occupation that is best to know about how to provide an optimum level of good care to the patient, because patients especially critically ill patients is depended on nursing care and to provide quality care, evidenced base knowledge is needed to guide nurses to fulfill their optimal task to quality improving through research (Buhaid et al., 2014).

Nursing research is defined as a systematic inquiry designed to develop knowledge about issues of importance to nurses, including nursing practice, nursing education and nursing administration. It is also directed towards promoting professional quality i.e. the credibility, accountability and cost effectiveness of nursing care (Nkrumah et al., 2018). It is a systematic approach used to examine phenomena important to nursing and nurses (Webb, 2011). Furthermore, nursing research help to develops and reforms necessary hands-on knowledge for clinical practice and provides evidence-based information to support nursing practices in the area of disease prevention and elimination of symptoms caused by illnesses.

Nursing research utilization is the system of synthesizing, disseminating or the use of research generated competencies to fulfill massive influence about the present day nursing (Nwozichi \& Ojewole, 2014). Nowadays, it's necessary for nurses to bring up to date their knowledge and skills due to rapid enhancement in technology and medical knowledge, this is only possible when nurses utilize the current knowledge into their practice (Kousar et al., 2017). To providing quality care, research utilization is very necessary (Heydari \& Zeydi, 2014). The profession needs to make use of research findings in maintaining its professional status and growth hence, researches are needed to be conducted as well as utilize in order to improve the quality of patient care (Nwozichi \& Ojewole, 2014). In different countries quality care is improved by the utilization of research findings into practices hence, it is very important for health care staff to appreciate and engage with scientific evidence through research (Nkrumah et al., 2018).

Several studies indicated that only few nurses participate and implement researches into their practices (Adejumo \& Guobadia, 2013; Mckee, 2017 \& Kousar et al., 2017). It was observed that it is only Nurses in the academic that get involved most in research why Nurses in the clinical areas seldom carry out research (Roll et al., 2013). They are only involve in research to fulfill a requirement to an educational certificate, they seldom read journal and make use of research findings to improve their practice (Agbedia et al., 2014) but looking at it, the present and future professional Nursing practice is lying solely on Conducting and utilizing research findings (Tingen et al., 2009) (Bahadori et al., 2016a) as research findings has many benefit such as reducing the cost of health care, increasing productivity of health care workers $(\mathrm{H}$. $\mathrm{Al}$ Ghabeesh, 2015) and promoting quality health care which will improve patient outcome among others (Bahadori et al., 2016b; Athanasakis, 2013).

Nursing procedures that is backed up with evidence based findings face some obstacles that prevent the implementation of research findings (Mahmoud \& Abdelrasol, 2019). It is therefore necessary to identify factors influencing nurses involvement in research and utilization of research findings towards proffering solutions and improvement of nurses in participating in research and making use of research finding towards improvement in Nursing profession. Hence, it is against this background the study assessed the factors influencing nurses' involvement in research and use of research findings. 
ISSN: 2689-9418

Volume 4, Issue 4, 2021 (pp. 59-69)

\section{Objective of the Study}

To determine the factors influencing nurses involvement in research and utilization of research findings among nurses of a Teaching Hospital, South-West, Nigeria.

\section{METHODOLOGY}

A descriptive design was employed in assessing the factors influencing nurses' involvement and utilization of research findings in a teaching hospital in South-West, Nigeria. The target populations were nurses working in the Teaching hospital. Sample Size of 198 and convenient sampling technique was used in selecting the sample for the study. The instrument used was a self-developed questionnaire. A smaller version of the study was conducted prior the main study using another settings with same characteristics. Responses from the study were used to assess the feasibility and the practicability of the research study.

The instrument used (questionnaire) was carefully constructed based on the objectives of the study after reviewing relevant literature. It was then subjected to scrutiny of expert in the field assessing the adequacy, appropriateness and completeness of the content of the instrument to ensure it measures the scope of coverage of the content area to be measured. All corrections was effected before administering the instrument to the respondents. Cronbach's alpha was used to determine the reliability index of the instrument; which reported a reliability coefficient of 0.875 which was interpreted to be high.

The respondents were met and the purpose and objectives of the research was explained to the respondents, research assistants were trained on how to administer instrument and collect it. Questionnaires were distributed to the nurses and were collected back immediately when they were completed. All the data that was collected through questionnaire was analyzed using SPSS package. The Hypothesis was tested using Chi-Square and results were presented in tables.

Permission was collected from hospital's ethical committee. The research subjects were properly informed on the goals and objective of the study, they were informed on their right to participate or refuse, informed consent was taken before their participation in the study, Anonymity of the respondents was ensured as well as confidentiality of the information. 
African Journal of Health, Nursing and Midwifery

ISSN: 2689-9418

Volume 4, Issue 4, 2021 (pp. 59-69)

www.abjournals.org

\section{PRESENTATION OF RESULTS}

\section{Demographic Characteristics}

Table 1: Number and Percentage of the Samples Classified by the Demographic Data

\begin{tabular}{|c|c|c|}
\hline Variables & Number & Percentage (\%) \\
\hline Age (n=198)* & 117 & 59.1 \\
$25-29$ & 62 & 31.3 \\
$30-39$ & 11 & 5.6 \\
$40-49$ & 8 & 4.0 \\
$\geq 50$ & 180 & \\
\hline Religion (n=198)* & 17 & 90.9 \\
Christianity & 1 & 8.6 \\
Islam & 108 & 0.5 \\
Traditional Worshipper & 88 & 54.6 \\
Marital Status (n=198)* & 1 & 44.4 \\
Single & 1 & 0.5 \\
Married & & \\
Divorced & 120 & 60.6 \\
Widowed & 59 & 29.8 \\
Educational Level (n=198)* & 9 & 4.5 \\
Registered nurse/ midwife & 10 & 5.1 \\
Bachelor in Nursing Science & & \\
Masters & 111 & 56.1 \\
Others & 57 & 28.8 \\
Level of Services (n=198)* & 26 & 13.1 \\
Below 5 years & 4 & 2 \\
5-10 years & & \\
11-20 years & & \\
21 years and above & & \\
\hline
\end{tabular}

Of the 198 respondents, the majority of the respondents fall within the age bracket of 25-29 years $(59.1 \% ; n=117)$, more than half of the respondents are Christians $(90.9 \% ; n=180)$, it is also notable that majority of the samples are single $(54.6 \% ; n=108)$. The majority of nurses' are either registered nurses or midwives $(60.6 \% ; n=120)$, with length of services mostly below 5 years $(56.1 \% ; \mathrm{n}=111)$.

Table 2: Showing number of Nurses' Involvement in Research and utilization of research findings

Did you carry out any research recently?

\begin{tabular}{|l|l|l|}
\hline Response & Frequency & Percentage (\%) \\
\hline YES & 45 & 22.7 \\
\hline NO & 153 & 77.3 \\
\hline TOTAL (n) & 198 & 100 \\
\hline
\end{tabular}


African Journal of Health, Nursing and Midwifery

ISSN: 2689-9418

Volume 4, Issue 4, 2021 (pp. 59-69)

www.abjournals.org

\begin{tabular}{|l|l|l|}
\hline Have you made use of any research findings? \\
\hline Response & Frequency & Percentage (\%) \\
\hline YES & 128 & 64.6 \\
\hline NO & 70 & 35.4 \\
\hline TOTAL $(\mathrm{n})$ & 198 & 99.5 \\
\hline
\end{tabular}

Table 2 shows that only 45 (22.7\%) of the participants nurses had carried out research recently, 153(77.3) have never carried out any research. It was observed also that $128(64.6 \%)$ have make use of research findings, 70 (35.4\%) have never make use of research findings.

Table 3: Showing respondents' responses on factors influencing Nurses involvement in research

\begin{tabular}{|l|l|l|}
\hline VARIABLES & YES f (\%) & NO f( \%) \\
\hline Unavailability of time to carry out research & $167(84.3 \%)$ & $31(15.7 \%)$ \\
\hline Organizational policy & $118(59.6 \%)$ & $80(40.4 \%)$ \\
\hline Lack of skills on how to carry out research & $120(60.6 \%)$ & $78(39.4 \%)$ \\
\hline Lack of mentor & $114(57.6)$ & $84(42.4)$ \\
\hline Lack of resources & $141(71.2 \%)$ & $57(28.8)$ \\
\hline Lack of fund & $156(78.8 \%)$ & $42(21.2 \%)$ \\
\hline Lack of knowledge of benefit of research & $103(52 \%)$ & $95(48 \%)$ \\
\hline Lack of support from colleagues & $113(57.1 \%)$ & $85(42.9 \%)$ \\
\hline Unavailability of research committee & $116(58.6 \%)$ & $82(41.4 \%)$ \\
\hline
\end{tabular}

From table 3, it shows that majority of respondents agreed that identified factors above in the table have influence on Nurses' involvement in research.

Table 4: Showing respondents' responses on factors that influence nurses utilization of research findings

\begin{tabular}{|l|l|l|}
\hline VARIABLES & YES f (\%) & NO f(\%) \\
\hline Lack of support and approval from organization & $122(61.6 \%)$ & $75(37.9 \%)$ \\
\hline Lack of awareness of the research finding & $121(61.1 \%)$ & $67(38.4 \%)$ \\
\hline Poor support/ cooperation from co- health worker & $129(65.1 \%)$ & $68(34.3 \%)$ \\
\hline $\begin{array}{l}\text { Administration would not allow implementation of } \\
\text { research findings }\end{array}$ & $95(48 \%)$ & $102(51.5 \%)$ \\
\hline Insufficient time on the job to read research findings & $127(64.1 \%)$ & $70(35.4 \%)$ \\
\hline Lack of knowledge of benefit of research & $109(55.1 \%)$ & $88(44.4 \%)$ \\
\hline Lack of support from colleagues & $112(56.6 \%)$ & $85(26.8 \%)$ \\
\hline Insufficient time on the job to implement new ideas & $144(72.7 \%)$ & $53(26.8 \%)$ \\
\hline Minimal authority on part of nurses to change procedure & $140(70.7 \%)$ & $57(28.8 \%)$ \\
\hline Research report not being published fast enough & $116(58.6 \%)$ & $81(40.9 \%)$ \\
\hline Research report not readily available & $102(51.5 \%)$ & $95(47.9 \%)$ \\
\hline Lack of research committee & $103(52.0 \%)$ & $94(47.5 \%)$ \\
\hline Inadequate facilities & $148(74.4 \%)$ & $49(24.7 \%)$ \\
\hline Implication of research to practice not being clear & $121(61.6 \%)$ & $76(38.3 \%)$ \\
\hline
\end{tabular}


African Journal of Health, Nursing and Midwifery

ISSN: 2689-9418

Volume 4, Issue 4, 2021 (pp. 59-69)

www.abjournals.org

\begin{tabular}{|l|l|l|}
\hline Isolation from knowledgeable colleague & $103(52.2 \%)$ & $94(47.5 \%)$ \\
\hline Research not relevant to practice & $92(46.5 \%)$ & $105(53 \%)$ \\
\hline
\end{tabular}

From table 4, it was observed that majority of the respondents disagreed that Administration would not allow implementation of research findings $102(51.5 \%)$ and Research not relevant to practice $105(53 \%)$ though responses though almost average to those that agreed to that points. Other variables were seen as factors that influence nurses' utilization of research findings

\section{Testing of Hypotheses}

Table 5: Showing chi-square testing showing relationship between independent variables and Nurses utilization of research findings.

\begin{tabular}{|c|c|c|c|c|}
\hline \multicolumn{4}{|c|}{$\begin{array}{l}\text { Relationship between research report not being published fast } \\
\text { enough and nurses' utilization of research findings }\end{array}$} & \multirow{5}{*}{$\frac{\text { P- value }}{0.000}$} \\
\hline Response & Frequency & \multicolumn{2}{|c|}{ Percentage $(\%)$} & \\
\hline YES & 117 & \multicolumn{2}{|c|}{59.1} & \\
\hline NO & 81 & \multicolumn{2}{|c|}{40.9} & \\
\hline $\begin{array}{l}\text { TOTAL } \\
\text { (n) }\end{array}$ & 198 & \multicolumn{2}{|c|}{100} & \\
\hline \multicolumn{4}{|c|}{$\begin{array}{l}\text { Relationship between insufficient time on the job to read research } \\
\text { findings and nurses' utilization of research findings }\end{array}$} & P-Value \\
\hline Response & Frequency & & Percentage $(\%)$ & \multirow{4}{*}{0.005} \\
\hline YES & 128 & & 64.6 & \\
\hline NO & 70 & & 35.4 & \\
\hline $\begin{array}{l}\text { TOTAL } \\
\text { (n) }\end{array}$ & 198 & & 100 & \\
\hline \multicolumn{4}{|c|}{$\begin{array}{l}\text { Relationship between organizational support and nurses' utilization } \\
\text { of research findings }\end{array}$} & P-Value \\
\hline Response & Frequency & & Percentage $(\%)$ & \multirow{4}{*}{0.001} \\
\hline YES & 123 & & 62.1 & \\
\hline $\mathrm{NO}$ & 75 & & 37.9 & \\
\hline $\begin{array}{l}\text { TOTAL } \\
\text { (n) }\end{array}$ & 198 & & 100 & \\
\hline \multicolumn{3}{|c|}{$\begin{array}{l}\text { Relationship between availability of } \\
\text { research committee and Nurses' } \\
\text { utilization of research findings }\end{array}$} & & P-Value \\
\hline Response & Frequency & & Percentage $(\%)$ & \multirow{4}{*}{0.000} \\
\hline YES & 104 & & 52.5 & \\
\hline NO & 94 & & 47.5 & \\
\hline $\begin{array}{l}\text { TOTAL } \\
\text { (n) }\end{array}$ & 198 & & 100 & \\
\hline
\end{tabular}


ISSN: 2689-9418

Volume 4, Issue 4, 2021 (pp. 59-69)

www.abjournals.org

The above table shows that there was a significant relationship between unpublished research and nurses' utilization of research findings as the p-value was 0.000 which is lower than 0.05 level of significance and this suggests that unpublished research influences nurses' utilization of research findings. Furthermore, there is a significant relationship between time to implement new ideas and the utilization of research findings by nurses. This implies time influences nurses' utilization of research findings. It was also observed that there was a significant relationship between organizational support and nurses' utilization of research findings as Chi test of this hypothesis showed a significance probability of 0.001 which was lower than 0.05 level of significance. Lastly there is significant relationship between the presence of research committee and nurses' utilization of research findings. The p-value was found to be 0.000 . This implies that the presence of research committee influences nurses' utilization of research findings

\section{DISCUSSION OF FINDINGS}

From Table 2, the study shows that only $45(22.7 \%)$ of the participants nurses had carried out research recently, 153(77.3) have not carried out any research. It was observed that 128 (64.6\%) said they make use of research findings, 70 (35.4\%) said they do not make use of research findings. The outcome of this study goes against the findings of (Agbedia et al., 2014; Edet et al., 2011; Nkrumah et al., 2018 \& Kousar et al., 2017) who reported that it was only few respondents that make use of research findings. However, the outcome of this research concur with the findings of (Oluwatosin, 2014) in a study carried on conduct and utilization of research among nurses as only $21.2 \%$ had conducted research, $31.4 \%$ had utilized research findings in clinical practice.

From table 3, it was observed that the reasons that were highlighted for non-participation in research include: Unavailability of time to carry out research, organizational policy, lack of mentor to teach research, lack of resources including fund, lack of knowledge of benefit of research, lack of support from colleague and unavailability of research committee. The outcome of this study support the findings of (Asuquo etal., 2013; Kousar et al.,2017; McKee et al., 2017; Nkrumah et al., 2018 \& Omer, 2012) that opined that lack of fund, lack of support and approval from organization, lack of research committee, lack of time on the job, lack of policy to promote research in their organization, lack of research resources was a barrier to participation in research and nurses capacity for health research and policy engagement in research. Also, Shifaza et al., (2014) and Almalki (2017) studies agrees with the outcome of this study by identifying feeling of inadequate knowledge and skills in carrying out of research in terms of writing research, interpretation of data, not working with colleagues that is knowledgeable as factors that impede participation in research .

From table 4, reasons identified to influence utilization of research findings include: lack of support and approval from organization, lack of awareness of the research finding, Poor support/ cooperation from co- health worker, insufficient time on the job to read research findings, lack of knowledge of benefit of research, lack of support from colleagues, insufficient time on the job to implement new ideas, minimal authority on part of nurses to change procedure, research report not being published fast enough, research report not readily available, lack of research committee, inadequate facilities, isolation from knowledgeable colleague. The outcome of this research goes in line with researches of various authors that 
ISSN: 2689-9418

Volume 4, Issue 4, 2021 (pp. 59-69)

revealed that organization influence, lack of research skill and development, lack of interest to read research papers, lack of authority, lack of time, insufficient understanding of research process and findings, lack of resources, and inadequate organizational support ( Abouelfettoh \& Ateeq, 2018; Adejumo \& Guobadia, 2013; Bahadori et al., 2016a \& Tan et al., 2012).

Also, the outcome of this study corroborate with the studies of (Abouelfettoh \& Ateeq, 2018; Heydari \& Zeydi, 2014; Kajermo et al., 1998; Kousar et al.,2017; Tuppal et al., 2019; Wang et al., 2013 \& Zhou et al., 2015) that identified organizational policy, lack of time on the job to read research findings, lack of authority to change patient procedure of care and administration not allowing implementation of research findings, lack of facilities ,perceived little benefit, respondents feel benefit of changing research will be minimal and not seeing the value of research for practice. Also, Oluwatosin (2014) considered time related issues as the leading barrier. Barriers such as facilities needed for implementing research findings, language barrier, lack of authority, time, isolation from other colleague, unavailability of research articles and nurses not willing to try new ideas have, lack of authority, lack of time and language barrier lack of funding, physician not cooperating, minimal authority on the part of the nurses to change procedure, insufficient time to implement research and managers not allowing implementation were identified as factors that hinders the participation and utilization of research findings by nurses.

Table 5 shows a significant relationship between between unpublished research and nurses' utilization of research findings ( $\mathrm{p}$-value was 0.000 ). This also validates another study carried out by KyaloMustisya et al., (2015) that documented that when research findings are not communicated through publishing, it may prevent it utilization as people will not get to know about the findings. Furthermore, the findings from table 5 suggest that there is a significant relationship between time to implement new ideas and the utilization of research findings by nurses. This goes in tandem with the study of Shifaza et al., (2014) and Behadori et al., (2016a) that narrated similar findings that majority of nurses in their study reported that there was no time on the job to read about new research findings and most times there are no time to implement the new method as there are a lot of procedures to be done. In addition, the hypothesis which stated that there is no significant relationship between organization support and nurses utilization of research findings was rejected as Chi test of this hypothesis showed a significance probability of 0.001 . this shows there is a significant relationship between organizational support and utilization of Research findings. The outcome of this study agree with the findings of Nkrumah etal., (2018) that related organizational support to utilization of research findings. Lastly there was a significant relationship between the presence of research committee and nurses' utilization of research findings. The p-value was found to be 0.000 . This implies that the presence of research committee influences nurses' utilization of research findings. Tawfik etal., (2014) identified not working together with knowledgeable colleagues as a barrier to utilization of research

\section{RECOMMENDATIONS}

1. Hospitals should make policies that will be favorable for nurses to participate in research and making use of research findings 
ISSN: 2689-9418

Volume 4, Issue 4, 2021 (pp. 59-69)

2. Seminars and trainings should be organized for nurses at their places of work to update their knowledge about research. Nurses that are knowledgeable about research should be encouraged to teach and mentor nurses.

3. Hospital management should make funds and grants available for nurses that are interested in participating in research.

4. More nurses should be employed to relieve nurses of their enormous work to have time to read about outcome of new researches and enable nurses have flexible time to participate in research

5. Journals should be procured monthly for Nurses and should be encouraged to read journals to keep themselves abreast of recent findings.

6. .Hospital management should provide fund for publishing of research carried out.

7. The hospital management should give incentives to nurses that participate in research.

8. Research committee should make protocols flexible to encourage nurse's participation in research.

\section{CONCLUSION}

Conducting research is one good way to strengthen critical thinking skills among health personnel. Health research also provides new knowledge, tools, and technologies to support knowledge-based development of nursing services. This study confirms the long held belief that few professional nurses providing nursing care in hospitals participate actively in conducting research. This could be an impediment to improving the quality of nursing care. Several factors contribute to this phenomenon, particularly the availability of funding support and research advisors, knowledge and skills in research methodology. This study identified variables such as time, organizational policy, mentorship, funds, knowledge of benefit of research as those factors affecting the involvement of nurses in research, and variables such as organizational approval and support, awareness of research findings, lack of support from colleagues, and insufficient time on job to implement new ideas as the major factors influencing nurses' utilization of research findings.

\section{REFERENCE}

Abouelfettoh, A., \& Ateeq, D. (2018). Nurses' KAP related to research conduct and utilization: EBNP "are we ready yet. International Journal of Advanced Nursing Studies, 7, 72. https://doi.org/10.14419/ijans.v7i1.11814

Adejumo, P. O., \& Guobadia, P. O. (2013). Nurses' attitude to reading research articles and their perception of research utilization in clinical practice in a Nigerian city. Journal of Medicine and Biomedical Research, 12(1), 46-56. https://doi.org/10.4314/jmbr.v12i1.

Agbedia, C., Okoronkwo, I., Onokayeigho, E., \& Agbo, M. A. (2014). Nurses' perspective of the research-practice gap in nursing. Open Journal of Nursing, 4(2), 720-726.

https://doi.org/10.4236/ojn.2014.42013 
African Journal of Health, Nursing and Midwifery

ISSN: 2689-9418

Volume 4, Issue 4, 2021 (pp. 59-69)

www.abjournals.org

Almalki, M. S. S. (2017). Barriers to and facilitators of research utilisation among nurses in Saudi Arabia.

https://researchrepository.rmit.edu.au/discovery/fulldisplay/alma9921864000501341/61 RMIT_INST:ResearchRepository

Asuquo, E., Etowa, J., John, M. E., Ndiok, A., Samson-Akpan, P., \& Edet, O. (2013). Assessing Nurses' Capacity for Health Research and Policy Engagement in Nigeria. Journal of Applied Medical Sciences, 2, 35-51.

Athanasakis, E. (2013). Nurses' Research Behavior and Barriers to Research Utilization Into Clinical Nursing Practice: A Closer Look. International Journal of Caring Sciences.

Bahadori, M., Raadabadi, M., Ravangard, R., \& Mahaki, B. (2016a). The barriers to the application of the research findings from the nurses' perspective: A case study in a teaching hospital. Journal of Education and Health Promotion, 5. https://doi.org/10.4103/2277-9531.184553

Bahadori, M., Raadabadi, M., Ravangard, R., \& Mahaki, B. (2016b). The barriers to the application of the research findings from the nurses' perspective: A case study in a teaching hospital. Journal of Education and Health Promotion, 5, 14. https://doi.org/10.4103/2277-9531.184553

Buhaid, N., Lau, R., \& O'connor, M. (2014). A survey of nurses' perceived barriers to research utilization in Bahrain in comparison to other countries. https://doi.org/10.5742/MEN.2014.92475

Edet, O., Ella, R., \& Esienumoh, E. (2011). Psychiatry Nurses' knowledge base, perceptions on research and research utilization in Calabar, Nigeria. INTERNATIONAL

PROFESSIONAL NURSING JOURNAL, VOL. 9, 112-119.

H. Al Ghabeesh, S. (2015). Barriers and Suggested Facilitators to the Implementation of Best Practice: An Integrative Review. Open Journal of Nursing, 05(01), 77-87. https://doi.org/10.4236/ojn.2015.51009

Heydari, A., \& Zeydi, A. E. (2014). Barriers to and Facilitators of Research Utilization among Iranian Nurses: A Literature Review. Journal of Caring Sciences, 3(4), 265. https://doi.org/10.5681/jcs.2014.029

Kousar, R., Kousar, R., Azhar, M., Waqas, A., \& Gilani, S. (2017). Barriers of Research Utilization in Nursing Practices in Public Hospitals in Lahore, Pakistan. International Journal of Applied Sciences and Biotechnology, 5, 243. https://doi.org/10.3126/ijasbt.v5i2.17627

Webb, J..J., (2011): Nursing research and evidenced base practice. $5^{\text {th }}$ Edition, St. Loius Mobsay

Kyalo Mutisya, A., KagureKarani, A., \& Kigondu, C. (2015). Research Utilization among Nurses at a Teaching Hospital in Kenya. Journal of Caring Sciences, 4(2), 95-104. https://doi.org/10.15171/jcs.2015.010

Mahmoud, M. H., \& Abdelrasol, Z. F. M. (2019). Obstacles in employing evidence-based practice by nurses in their clinical settings: A descriptive study. Frontiers of Nursing, 6(2), 123-133. https://doi.org/10.2478/FON-2019-0019

McKee, G., Codd, M., Dempsey, O., Gallagher, P., \& Comiskey, C. (2017). Describing the implementation of an innovative intervention and evaluating its effectiveness in increasing research capacity of advanced clinical nurses: Using the consolidated framework for implementation research. BMC Nursing, 16(1), 21. https://doi.org/10.1186/s12912-017-0214-6 
African Journal of Health, Nursing and Midwifery

ISSN: 2689-9418

Volume 4, Issue 4, 2021 (pp. 59-69)

www.abjournals.org

Nilsson Kajermo, K., Nordström, G., Krusebrant, A., \& Björvell, H. (1998). Barriers to and facilitators of research utilization, as perceived by a group of registered nurses in Sweden. Journal of Advanced Nursing, 27(4), 798-807. https://doi.org/10.1046/j.13652648.1998.00614.x

Nkrumah, I., Atuhaire, C., Priebe, G., \& Cumber, S. N. (2018). Barriers for nurses' participation in and utilisation of clinical research in three hospitals within the Kumasi Metropolis, Ghana. The Pan African Medical Journal, 30.

https://doi.org/10.11604/pamj.2018.30.24.15230

Nwozichi, C., \& Ojewole, F. O. (2014). PERCEIVED RESEARCH UTILIZATION

BARRIERS AMONG NURSES IN A RURAL HOSPITAL IN NIGERIA. /paper/PERCEIVED-RESEARCH-UTILIZATION-BARRIERS-AMONG-IN-ANwozichi-Ojewole/38dec2165fc2a27506de07aedba026b11043bb4f

Oluwatosin, A. O. (2014). Conduct and utilization of research among nurses at federal capital territory, Abuja Nigeria. https://doi.org/10.5430/jnep.v4n7p139

Omer, T. (2012). Research Utilization in a Multicultural Nursing Setting in Saudi Arabia. The Journal of Nursing Research: JNR, 20, 66-73. https://doi.org/10.1097/JNR.0b013e31824777d8

Roll, L., Stegenga, K., Hendricks-Ferguson, V., Barnes, Y. J., Cherven, B., Docherty, S. L., Robb, S. L., \& Haase, J. E. (2013). Engaging nurses in research for a randomized clinical trial of a behavioral health intervention. Nursing Research and Practice, 2013, 183984. https://doi.org/10.1155/2013/183984

Shifaza, F., Evans, D., \& Bradley, H. (2014). Nurses' Perceptions of Barriers and Facilitators to Implement EBP in the Maldives [Research Article]. Advances in Nursing; Hindawi. https://doi.org/10.1155/2014/698604

Tan, M., Sahin, Z. A., \& Özdemir, F. K. (2012). Barriers of research utilization from the perspective of nurses in Eastern Turkey. Nursing Outlook, 60(1), 44-50. https://doi.org/10.1016/j.outlook.2011.07.002

Tawfik, M. Y., Mohamed, N. I., \& Moussa, M. M. M. (2014). Barriers And Facilitates Of Research Utilization As Perceived By Nurses Of Suez Canal University HospitalIsmailia-Egypt. Kufa Journal for Nursing Sciences, 4(1). https://www.iasj.net/iasj/article/88995

Tingen, M. S., Burnett, A. H., Murchison, R. B., \& Zhu, H. (2009). The Importance of Nursing Research. The Journal of Nursing Education, 48(3), 167-170.

Tuppal, C. P., Vega, P. D., Ninobla, M. M. G., Reñosa, M. D., Al-Battashi, A., Arquiza, G., \& Baua, E. P. (2019). Revisiting the Barriers to and Facilitators of Research Utilization in Nursing: A Systematic Review. Nurse Media Journal of Nursing, 9(1), 90-102. https://doi.org/10.14710/nmjn.v9i1.20827

Wang, L.-P., Jiang, X.-L., Wang, L., Wang, G.-R., \& Bai, Y.-J. (2013). Barriers to and Facilitators of Research Utilization: A Survey of Registered Nurses in China. PLOS ONE, 8(11), e81908. https://doi.org/10.1371/journal.pone.0081908

Zhou, F., Maier, M., Hao, Y., Tang, L., Guo, H., Liu, H., \& Liu, Y. (2015). Barriers to Research Utilization among Registered Nurses in Traditional Chinese Medicine Hospitals: A Cross-Sectional Survey in China [Research Article]. Evidence-Based Complementary and Alternative Medicine; Hindawi. https://doi.org/10.1155/2015/475340 